\title{
Localization and Distribution of Wheat dwarf virus in Its Vector Leafhopper, Psammotettix alienus
}

\author{
Yajiao Wang, Qianzhuo Mao, Wenwen Liu, ThiThi Mar, Taiyun Wei, Yan Liu, and Xifeng Wang
}

First, third, fourth, sixth, and seventh authors: State Key Laboratory for Biology of Plant Diseases and Insect Pests, Institute of Plant Protection, Chinese Academy of Agricultural Sciences, Beijing 100193; and second and fifth authors: Fujian Province Key Laboratory of Plant Virology, Institute of Plant Virology, Fujian Agriculture and Forestry University, Fuzhou 350002, China.

Accepted for publication 28 January 2014.

\begin{abstract}
Wang, Y., Mao, Q., Liu, W., Mar, T., Wei, T., Liu, Y., and Wang, X. 2014. Localization and distribution of Wheat dwarf virus in its vector leafhopper, Psammotettix alienus. Phytopathology 104:897-904.

Numerous virus pathogens are transmitted by specific arthropod vectors. Understanding the mechanism of transmission is a critical step in the epidemiology of plant viruses and is crucial for the development of effective disease control strategies. In this study, we describe the localization and distribution of Wheat dwarf virus (WDV), an economically important and widespread single-stranded DNA virus, in its leafhopper vector, Psammotettix alienus. The results suggest that WDV not only can

move to the salivary glands from the anterior and middle midgut via the hemocoel but also can pass directly through the sheath of the filter chamber and be readily transmitted to healthy wheat plants within 5 min of an acquisition access period on infected plants. When a bacterial-expressed recombinant capsid protein $(\mathrm{CP})$ was incubated with the internal organs of leafhoppers, $\mathrm{CP}$-immunoreactive antigens were found at the anterior and middle midgut. Furthermore, when leafhoppers were fed with an antiserum raised against the $\mathrm{CP}$, the accumulation of WDV in the gut cells, hemocoel, and salivary glands was significantly reduced. These data provide evidence that transmission of WDV is determined by a CPmediated virion-vector retention mechanism.
\end{abstract}

The family Geminiviridae comprises seven genera: Begomovirus, Curtovirus, Topocuvirus, Mastrevirus, Becurtovirus, Turncurtovirus, and Eragrovirus (4). Viruses in the genus Mastrevirus, including Wheat dwarf virus (WDV), infect cereals and are transmitted by leafhoppers (Cicadellidae) in a persistent circulative manner (10). Many leafhopper-transmitted geminiviruses have one principal vector. The insect vector for WDV is Psammotettix alienus; Circulifer tenellus is the vector for Beet curly top virus and Cicadulina mbila for Maize streak virus (MSV) (22).

WDV was first described by Vacke (32) in the western parts of the former Czechoslovak Socialist Republic and was later found in many parts of the world (26). WDV has a monopartite, circular DNA genome encoding four proteins, including the capsid protein (CP) and the movement protein on the viral-sense strand and two replication-associated proteins (Rep and RepA) on the complementary strand $(8,25)$. During the last two decades, WDV has emerged as a devastating pathogen, threatening wheat and barley production and causing huge economic losses in Europe, Asia, and Africa (15,21,34). An important contributing factor for disease epidemics is the occurrence and expanded distribution of the leafhopper vector.

WDV is transmitted in a persistent manner by the leafhopper but the virus does not multiply within the insect and is not transmitted to the eggs (36). The digestive apparatus of the leafhopper vector consists of the esophagus, filter chamber, midgut, hindgut, and Malpighian tubules. A common sheath, composed of muscles and thin epithelial cells, surrounds the filter chamber, enclosing the top of the anterior midgut, the posterior midgut, and the origin

Corresponding author: X. Wang; E-mail address: xfwang@ippcaas.cn

*The $\boldsymbol{e}$-Xtra logo stands for "electronic extra" and indicates that Figures 1, 2, 3, and 4 appear in color online.

http://dx.doi.org/10.1094/PHYTO-09-13-0251-R

(c) 2014 The American Phytopathological Society and proximal ends of the Malpighian tubules. The midgut is divided into three parts: anterior, middle, and posterior (31). Parts of the anterior and posterior midguts, the anterior part of the hindgut, and the proximal part of the Malpighian tubules are all enclosed in a sheathed filter chamber (30).

Information regarding the interaction of cereal-infecting geminiviruses with their leafhopper vectors has come mainly from studies on MSV and its leafhopper vector, $C$. mbila. The vesicles packed with MSV inclusions were described in the filter chamber of $C$. mbila (16). The localization and distribution of MSV within C. mbila, monitored with quantitative polymerase chain reaction (PCR), showed that MSV accumulates mainly in the gut (14). A large number of inclusion bodies containing MSV particles were distributed in the epithelial cells of the filter chamber and midgut of their insect vectors $(1,17)$. Until now, information on the distribution of WDV within its insect vector has been very scarce.

In this report, we used immunofluorescence staining and a quantitative PCR to provide insights into the distribution of WDV in its leafhopper vector. We also provide biological and molecular evidence that transmission of WDV is determined by a CPmediated virion-vector retention mechanism.

\section{MATERIALS AND METHODS}

The source of virus and its insect vector. The isolate of WDV collected from Taiyuan, China, was identified using doubleantibody sandwich enzyme-linked immunosorbent assay and PCR with primers designed in the $\mathrm{CP}$ gene and sequencing (35). The virus was maintained on the susceptible wheat (Triticum aestivum L.) 'Yangmai 12' inoculated by viruliferous leafhoppers ( $P$. alienus L.). The insect colony ( $P$. alienus) used in our studies was collected in 2010 from Hancheng, Shaanxi Province, China, and has been reared on healthy wheat plants (Yangmai 12) in our laboratory for several years using an insect-proof containment chamber at a temperature of $25^{\circ} \mathrm{C}$ and a photoperiod of 17 and $7 \mathrm{~h}$ (day and night, respectively). 
Recombinant proteins and antibodies. Primers were designed based on the sequence of the CP gene (GenBank accession number JQ836568) of WDV (CP-F: 5'-GGGGACAAGTTTGTACAAAAA AGCAGGCTTCATGGTGACCAACAAGGACTCCCGAG-3'; CPR: 5'-GGGGACCACTTTGTACAAGAAAGCTGGGTCTTAT TGAATCCCAATGGATTTGAAG-3') and the Rep gene (GenBank accession number AM942045.1) of WDV (Rep-F: 5'-GGGG ACAAGTTTGTACAAAAAAGCAGGCTTCATGGCCTCTTCT GCACC-3'; Rep-R: 5'-GGGGACCACTTTGTACAAGAAAGC TGGGTCTCACTGCGAAGCAGTGACAT-3'). The CP and Rep genes were amplified by PCR, and the products were purified and engineered into the Gateway vector pDEST17 (Invitrogen, Carlsbad, CA). The resulting plasmids pDEST17-CP and pDEST17Rep were used to transform the Rosetta strain of Escherichia coli and expressed by adding isopropyl $\beta$-D-1-thiogalactopyranoside at $1 \mathrm{mmol} /$ liter (Sigma-Aldrich, St. Louis). Transformed cells were harvested and sonicated. CP or Rep protein was purified from the final suspension using Ni-NTA resin (Qiagen, Hilden, Germany). Polyclonal antisera against CP and Rep of WDV were prepared by immunizing rabbits with the purified proteins, as described previously (28). Immunoglobulin $\mathrm{G}(\mathrm{IgG})$ was isolated from specific polyclonal antisera using a protein A-Sepharose affinity column (Sigma-Aldrich). Eluted IgG was extensively dialyzed against phosphate-buffered saline (PBS) (13). To determine the specificity of anti-CP and anti-Rep antibodies by Western blot, we extracted the total proteins from $1 \mathrm{~g}$ of either WDV-infected or healthy wheat plants, separated them by sodium dodecyl sulfate polyacrylamide gel electrophoresis, and transferred them to a polyvinylidene diflouride membrane for detection, as described previously (29).

Feeding and dissecting the leafhopper vector, $P$. alienus. Second-instar nymphs of leafhoppers ( $n=30$, three repetitions) from our colony were starved for $2 \mathrm{~h}$, then allowed a 5-min acquisition access period (AAP) on WDV-infected wheat plants before placing them on healthy wheat seedlings in a growth chamber at $25^{\circ} \mathrm{C}$ for $17 \mathrm{~h}$ of light and $7 \mathrm{~h}$ of darkness. At different times after this AAP on the diseased plants (post access to diseased plants [PADP]), the head-prothorax portion of the leafhoppers was separated, and the drops of hemolymph oozing from the exposed part of the mesothorax were quickly collected. The internal organs, including the salivary glands, filter chamber, midgut, Malpighian tubules, and hindgut, were then dissected under a stereomicroscope with the aid of forceps.

Immunofluorescence staining of the internal organs of $P$. alienus after virus acquisition. The dissected organs were fixed in $4 \%$ paraformaldehyde, then washed in $0.01 \mathrm{M} \mathrm{PBS,} \mathrm{pH}$ 7.4, and permeabilized in PBS containing 2\% Triton X-100 for $2 \mathrm{~h}$ at room temperature. These organs were washed and immersed in a $1 / 20$ dilution of the rabbit antiserum to WDV for $1 \mathrm{~h}$ at $37^{\circ} \mathrm{C}$. They were washed with PBS, then incubated for $1 \mathrm{~h}$ at $37^{\circ} \mathrm{C}$ with a $1 / 200$ dilution of goat anti-rabbit $\mathrm{IgG}$ conjugated with fluorescein-5-isothiocyanate (Sigma-Aldrich) and the actinspecific dye phalloidin-rhodamine (Sigma-Aldrich) to aid in identifying various tissues during microscopic examination. Finally, the organs were washed with PBS, then examined using a TCS SP5 confocal laser-scanning microscope (CLSM) (Leica, Wetzlar, Germany), as described previously (6). Leafhoppers feeding on healthy wheat plants were similarly processed and examined as negative controls.

Immunofluorescence staining of hemocyte smears. The collected hemolymph drops were quickly smeared on poly (L-lysine)-coated cover glasses. The glasses were incubated at $37^{\circ} \mathrm{C}$ for $45 \mathrm{~min}$ to allow the adhesion of hemocyte, then processed and examined using CLSM as described above (7).

Transmission assay of WDV by the leafhopper vector, $P$. alienus. Second-instar nymphs of $P$. alienus $(n=30$, three repetitions) from our colony were allowed a 5-min AAP on WDVinfected wheat plants; then, each insect was individually placed in a tube with a healthy wheat plant (Yangmai 12) for different durations. Each leafhopper was subsequently anesthetized with $\mathrm{CO}_{2}$ (2) and the inoculated plant was removed from the tube, transplanted to a pot, and moved to a greenhouse at $25^{\circ} \mathrm{C}$ and a photoperiod of 17 and $7 \mathrm{~h}$ (day and night, respectively). Inoculated plants were monitored for symptom development for 2 weeks; then, leaf tissue was sampled for PCR. Leafhoppers feeding on healthy wheat plants were treated similarly as negative controls.

Quantification of WDV DNA copies in the internal organs of leafhoppers after virus acquisition. The internal organs (filter chamber, midgut, hemocoel, and salivary glands) of leafhoppers were tested in groups of 30 insects (three repetitions). To wash unbound or nonspecifically bound virions in the lumen of the alimentary canal, the filter chamber and midgut were cut open gently with dissecting needles and washed with PBS several times. Total DNA of the different internal organs were extracted with the Wizard Genomic DNA Purification Kit (Promega Corp., Madison, WI). DNA amplifications carried out with $2 \mu \mathrm{l}$ of total DNA in a volume of $20 \mu \mathrm{l}$ were done with the Premix EX Taq Kit (TaKaRa, Madison, WI), with the primers of the sequences of the CP gene (GenBank accession number JQ836568) of WDV (CP-F: 5'-CTGCTATATGTCCGATGCATCAG-3'; CP-R: 5'-CTGCAT CATAGACTAACCAGTGGTAGA-3'). PCR amplification consisted of an initial 15 -min denaturation step at $95^{\circ} \mathrm{C}$ followed by 40 cycles of $10 \mathrm{~s}$ at $95^{\circ} \mathrm{C}, 60 \mathrm{~s}$ at $58^{\circ} \mathrm{C}$, and $30 \mathrm{~s}$ at $72^{\circ} \mathrm{C}(36)$. Leafhoppers feeding on healthy wheat plants were treated similarly as negative controls.

The standard plasmids pDEST17-CP, prepared as described above, were used in 10-fold serial dilutions to generate standard curves to determine the assay efficiency and quantify the viral target in the unknown samples.

Internal organs incubated with recombinant protein. Internal organs were excised from three groups of second-instar nymphs of leafhoppers ( $n=30$, three repetitions), fixed in $4 \%$ paraformaldehyde (vol/vol), then washed with $0.01 \mathrm{M}$ PBS and permeabilized in $2 \%$ Triton X-100. They were washed and incubated with recombinant $\mathrm{CP}$, recombinant Rep, or purified WDV virions as a positive control. Finally, the organs were washed, and samples were stained with the corresponding IgG (anti-CP, anti-Rep, or anti-WDV), then processed for CLSM (6).

Serological infectivity neutralization experiments. Secondinstar nymphs of leafhoppers were fed with antisera-WDV CP, antisera-WDV-Rep, or basal artificial diet as a negative control $(19,0)$ for 1 day, then allowed a 5-min AAP on WDV-infected wheat plants, before being placed on healthy wheat seedlings. At 5, 10, and 20 min PADP, we excised the internal organs from 30 feeding leafhoppers (three repetitions) and processed them for CLSM (7). Inoculated plants were monitored for symptom development for 2 weeks; then, leaves were sampled for PCR.

The excised filter chamber and midgut of feeding leafhoppers were cut open gently with dissecting needles and washed with PBS several times to flush out unbound or nonspecifically bound virions in the alimentary canal. Total DNA of the internal organs dissected from 30 insects (three repetitions) was extracted and analyzed by real-time PCR. The primers for sequences of the $\mathrm{CP}$ gene of WDV (the same as above in the experiment of real-time PCR ) and internal reference cytochrome oxidase subunit I (COI) gene (GenBank accession number JN391184.1) of leafhoppers (COI-F: 5'-CACAAGAAAGAGGGAAAACAGAATC-3'; COIR: 5'-AGCTCGTGTGTCAACATCTATTCCT-3') were designed and analyzed by real-time PCR, as described previously.

\section{RESULTS}

The progression and circulation of WDV through its leafhopper vector. To investigate the progression and circulation of WDV in the leafhopper vectors, CLSM was used to detect the distribution of viral antigens in the leafhopper at $0,5,10,20$, and 

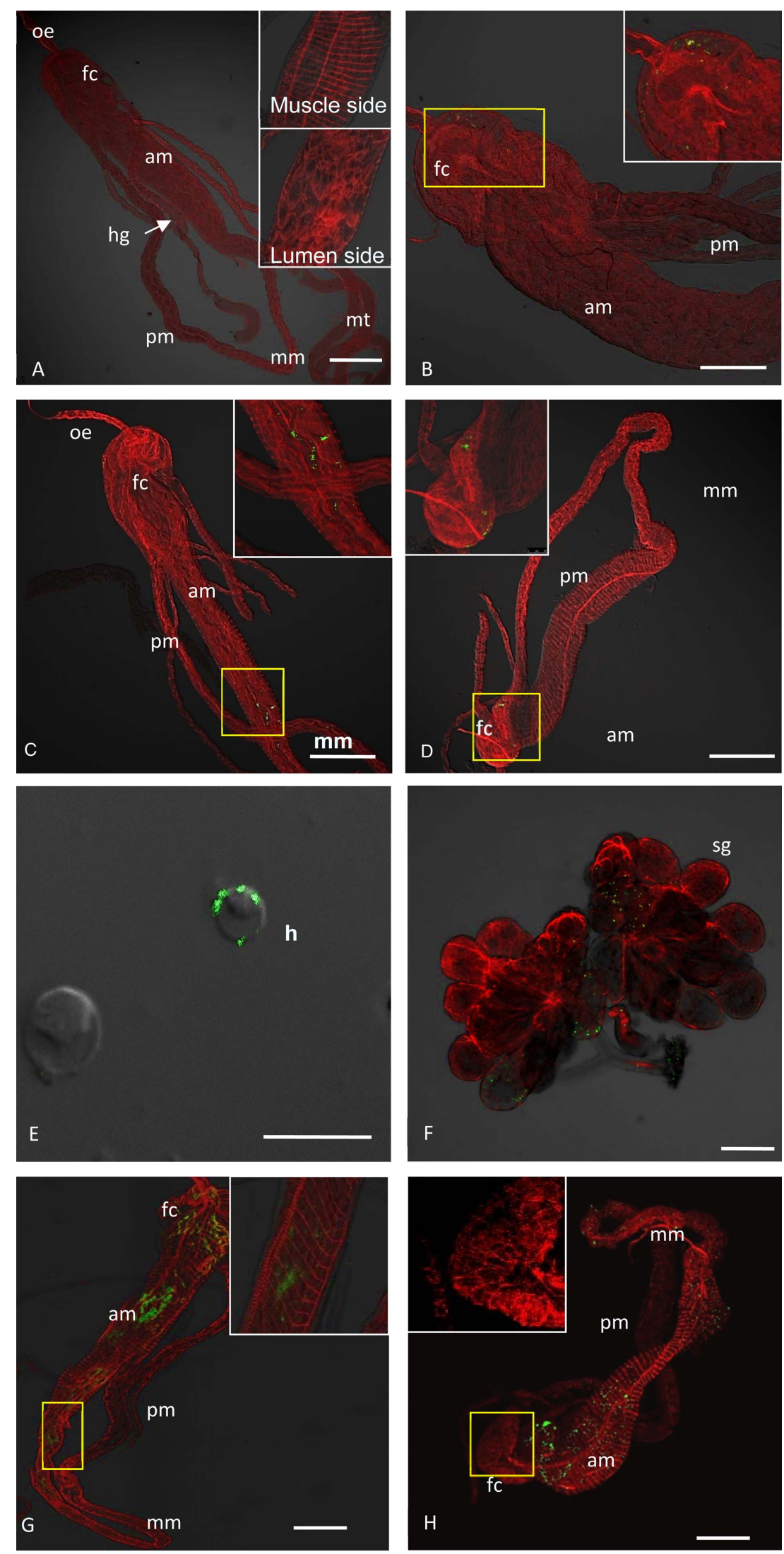

Fig. 1. Wheat dwarf virus (WDV) accumulation in various organs and tissues of the leafhopper vector, Psammotettix alienus. Leafhopper organs and hemocytes were excised and immunolabeled for WDV with fluorescein-5-isothiocyanate (green) and stained for actin with phalloidin-rhodamine (red), then examined by confocal microscopy. A, Negative control (aviruliferous leafhopper). View of partially dissected alimentary canal of nonviruliferous leafhopper, showing the esophagus (oe); filter chamber (fc); anterior (am), middle (mm), and posterior midgut (pm); hindgut (hg); and Malpighian tubules (mt). B, At 0 min post access to diseased plants (PADP), WDV was detected in the lumen of the filter chamber (fc). C, At 5 min PADP, WDV had spread to the lumen of the midgut. D, At 10 min PADP, WDV was detected in the sheath of the filter chamber, and also in $\mathbf{E}$, some hemocytes (h) and $\mathbf{F}$, the salivary glands (sg). G, At 20 min PADP, WDV was detected in the muscle of the anterior and middle midgut. H, At $4 \mathrm{~h}$ PADP, virus was absent from the filter chamber and only detected in cells of the anterior and middle midgut. 
240 min after the 5-min AAP on WDV-infected plants. In the excised internal organs of the leafhopper $(n=30$, three repetitions) in CLSM, specific labeling of the viral antigens was observed in the lumen of the filter chamber in $50 \%$ of the examined leafhoppers at 0 min PADP (Fig. 1B; Table 1). At 5 min PADP, WDV antigens were found in the sheath of the filter chamber and the gut lumen in 45.6 and $54.4 \%$ of the examined leafhoppers, respectively (Fig. 1C and D), whereas no virus accumulation was found in the muscle of the midgut. We also found WDV antigens in the hemocoel and the salivary glands in $13.3 \%$ of the leafhoppers examined at this time (Fig. 1E and F; Table 1). All these observations suggested that virus first spread to the salivary glands through the filter chamber via the hemocoel. At 10 min PADP, WDV had spread into the muscle of the anterior and middle midgut in $\approx 12.2 \%$ of the leafhoppers, and in $53.3 \%$ at 20 min PADP (Fig. 1G; Table 1). At 4 h PADP, viral antigens were not found in the sheath of the filter chamber but were present in large numbers in the muscle of the anterior and middle midgut, hemocoel, and salivary glands (Fig. 1H; Table 1). These results indicated that the virus cleared quickly from the filter chamber and then spread to the salivary glands through the anterior and middle parts of the midgut at $4 \mathrm{~h}$ PADP. Viral antigens were not detected in the muscle of the posterior midgut, hindgut, or Malpighian tubules at any time (Table 1). Virus antigens were not detected at any time in aviruliferous leafhoppers used as a negative control (Fig. 1A). These results suggested that WDV can rapidly and temporarily invade the salivary glands via the hemocoel after circulating from the filter chamber of its leafhopper vector. Furthermore, the virus can also pass from the anterior and middle midgut to the salivary glands via the hemocoel using wellknown pathways described for other leafhopper-transmitted persistent circulative viruses (7).

The progression of WDV spread observed in the leafhopper was further confirmed using a quantitative real-time PCR assay. At 0 min PADP, the number of WDV DNA copies detected in the filter chamber, midgut, hemocoel, and salivary glands were all within 100. The number of WDV DNA copies in counterpart organs from nonviruliferous leafhoppers was $<100$; therefore, an absence of WDV was considered if the number was <100 (Fig. 2). At 5 min PADP, the number of WDV DNA copies remained stable in the midgut but rapidly increased in the filter chamber, hemocoel, and salivary glands (Fig. 2), suggesting that WDV escaped from the filter chamber barrier, spread into the hemocoel, and arrived at the salivary glands. At $10 \mathrm{~min}$ PADP, the copy number of the WDV DNA remained stable in the filter chamber but rapidly increased in the midgut and continued increasing in the hemocoel (Fig. 2), suggesting that WDV escaped the midgut barrier and spread into the salivary glands through the hemocoel, resulting in a continued increase of WDV DNA copy numbers in the salivary glands. At $4 \mathrm{~h}$ PADP, the number of WDV DNA copies in the filter chamber fell to 29 (Fig. 2), suggesting that the virus was cleared from the filter chamber, which was used only as a temporary channel for WDV spread to the salivary glands via the hemocoel. Also, the DNA copy number in the midgut, filter chamber, and salivary glands remained stable (Fig. 2). These results suggested that WDV mainly spread to the salivary glands via the hemocoel through the midgut at $4 \mathrm{~h}$ PADP.

Transmission assay for leafhopper infectivity. Second-instar nymphs of leafhoppers ( $n=30$, three repetitions) allowed a 5-min AAP on WDV-infected wheat plants were transferred to healthy wheat seedlings for a different inoculation access period. Two weeks later, $11.7 \%$ of the plants with a $5-\min$ PADP, $25.6 \%$ of the plants with a 10 -min PADP, $46.7 \%$ of those with a 20 -min PADP, and $58.9 \%$ with a 240 -min PADP were infected by WDV, as indicated by PCR analysis (Table 1). None of the negative control plants were infected.

The CP is the determinant that participates in WDV retention and transmission. The above data indicated that WDV virions move through and are retained in the filter chamber and midgut of the leafhopper vector. This scenario suggested that determinants encoded by WDV might function in the specific recognition of movement and retention sites within the leafhopper. Consequently, we conducted recombinant protein-incubation experiments to confirm the hypothesis that the $\mathrm{CP}$ is involved in the retention of WDV in its vector. We found that fluorescent signals were observed in the anterior and middle midgut of the insect after incubation with WDV or with CP (Fig. 3A and B). No fluorescent signals were detected after incubation with Rep (Fig. 3C). In most cases, the signals seen in the WDV-incubated organs occurred in large areas of the anterior and middle midgut but the signals in the CP-incubated organs were seen in a much smaller area. Our results indicated clearly that the $\mathrm{CP}$ was involved in the retention of WDV in the leafhopper internal organs.

Ingestion of antiserum to WDV CP strongly inhibits virus transmission in the leafhopper vector. Serological infectivity neutralization (SIN) experiments were used to confirm the role of WDV CP in transmission. At 5 min PADP, WDV antigens were found in the lumen of the alimentary canal in $51.1 \%$ of basal dietfed leafhoppers and in $48.9 \%$ of CP antisera-fed leafhoppers (Table 2). At 10 min PADP, WDV had spread to the sheath of the filter chamber in $53.3 \%$ of basal diet-fed leafhoppers (Fig. 4B; Table 2) but only in $8 \%$ of the CP-antisera-fed leafhoppers (Fig.

TABLE 1. Localization and distribution of Wheat dwarf virus (WDV) in various organs of its vector Psammotettix alienus at different acquisition access periods revealed by confocal laser-scanning microscopy ${ }^{\mathrm{x}}$

\begin{tabular}{|c|c|c|c|c|c|}
\hline \multirow[b]{2}{*}{ Organs/tissues examined ${ }^{y}$} & \multicolumn{5}{|c|}{ P. alienus organs containing WDV at the indicated minutes PADP $(\%)^{\mathrm{z}}$} \\
\hline & $0 \mathrm{~min}$ & $5 \min$ & $10 \min$ & $20 \mathrm{~min}$ & $240 \mathrm{~min}$ \\
\hline Lumen of esophagus & $25.6 \mathrm{a}$ & $0.0 \mathrm{a}$ & $0.0 \mathrm{a}$ & $0.0 \mathrm{a}$ & $0.0 \mathrm{a}$ \\
\hline Lumen of filter chamber & $50.0 \mathrm{~b}$ & $54.4 \mathrm{~b}$ & $51.1 \mathrm{~b}$ & $53.3 \mathrm{~b}$ & $0.0 \mathrm{a}$ \\
\hline Lumen of midgut & $25.6 \mathrm{a}$ & $54.4 \mathrm{~b}$ & $51.1 \mathrm{~b}$ & $53.3 \mathrm{~b}$ & $68.9 \mathrm{~b}$ \\
\hline Sheath of filter chamber & $0.0 \mathrm{~d}$ & $45.6 \mathrm{~d}$ & $51.1 \mathrm{~b}$ & $53.3 \mathrm{~b}$ & $0.0 \mathrm{a}$ \\
\hline Cells of midgut & $0.0 \mathrm{~d}$ & $0.0 \mathrm{a}$ & $12.2 \mathrm{c}$ & $53.3 \mathrm{~b}$ & $68.9 \mathrm{~b}$ \\
\hline Hemocoel & $0.0 \mathrm{~d}$ & $13.3 \mathrm{e}$ & $48.9 \mathrm{~b}$ & $53.3 \mathrm{~b}$ & $53.3 \mathrm{~b}$ \\
\hline Salivary glands & $0.0 \mathrm{~d}$ & $13.3 \mathrm{e}$ & $48.9 \mathrm{~b}$ & $53.3 \mathrm{~b}$ & $53.3 \mathrm{~b}$ \\
\hline Muscle of posterior midgut & $0.0 \mathrm{~d}$ & $0.0 \mathrm{a}$ & $0.0 \mathrm{a}$ & $0.0 \mathrm{a}$ & $0.0 \mathrm{a}$ \\
\hline Malpighian tubules & $0.0 \mathrm{~d}$ & $0.0 \mathrm{a}$ & $0.0 \mathrm{a}$ & $0.0 \mathrm{a}$ & $0.0 \mathrm{a}$ \\
\hline Cells of hindgut & $0.0 \mathrm{~d}$ & $0.0 \mathrm{a}$ & $0.0 \mathrm{a}$ & $0.0 \mathrm{a}$ & $0.0 \mathrm{a}$ \\
\hline Infected plant & 0.0 & 11.7 & 25.6 & 46.7 & 58.9 \\
\hline
\end{tabular}

$x$ Virus was detected in leafhoppers by confocal microscopy at 0-240 min following a 5-min acquisition access period (AAP) on WDV-infected wheat plants.

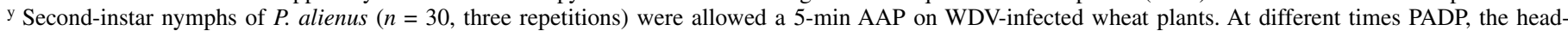
prothorax area of the leafhoppers was excised, and hemolymph oozing from the exposed part of the mesothorax was quickly collected; internal organs, including the salivary glands, filter chamber, midgut, Malpighian tubules, and hindgut, were then excised using a stereomicroscope and forceps.

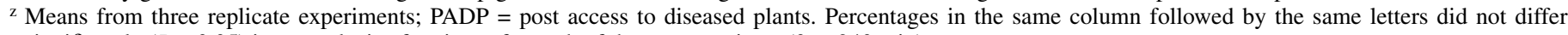
significantly $(P>0.05)$ in an analysis of variance for each of the separate times (0 to $240 \mathrm{~min})$. 
4A; Table 2), suggesting that the WDV CP antiserum can prevent the interaction between the virus and its potential receptors in the filter chamber of its insect vector and that most of the WDV distributed in the lumen of the gut could not spread to the sheath of the filter chamber. At $20 \mathrm{~min}$ PADP, WDV was found in the muscle of the anterior and middle midgut in $54.4 \%$ of basal dietfed leafhoppers (Fig. 4D; Table 2) but in only $15.6 \%$ of antiWDV CP-fed leafhoppers (Fig. 4C; Table2). This result suggested that the WDV CP antiserum prevented the virus from interacting with potential receptors in the gut of the insect vector, resulting in most of the WDV particles being excreted. No significant differences were found between the leafhoppers that ingested the WDV-Rep antiserum and the basal diet (Table 2).

The transmission assay data were in agreement with those of the SIN experiment. When leafhoppers were fed the basal diet, the infection rate of the wheat plants was $8.9 \%$ when the leaf-
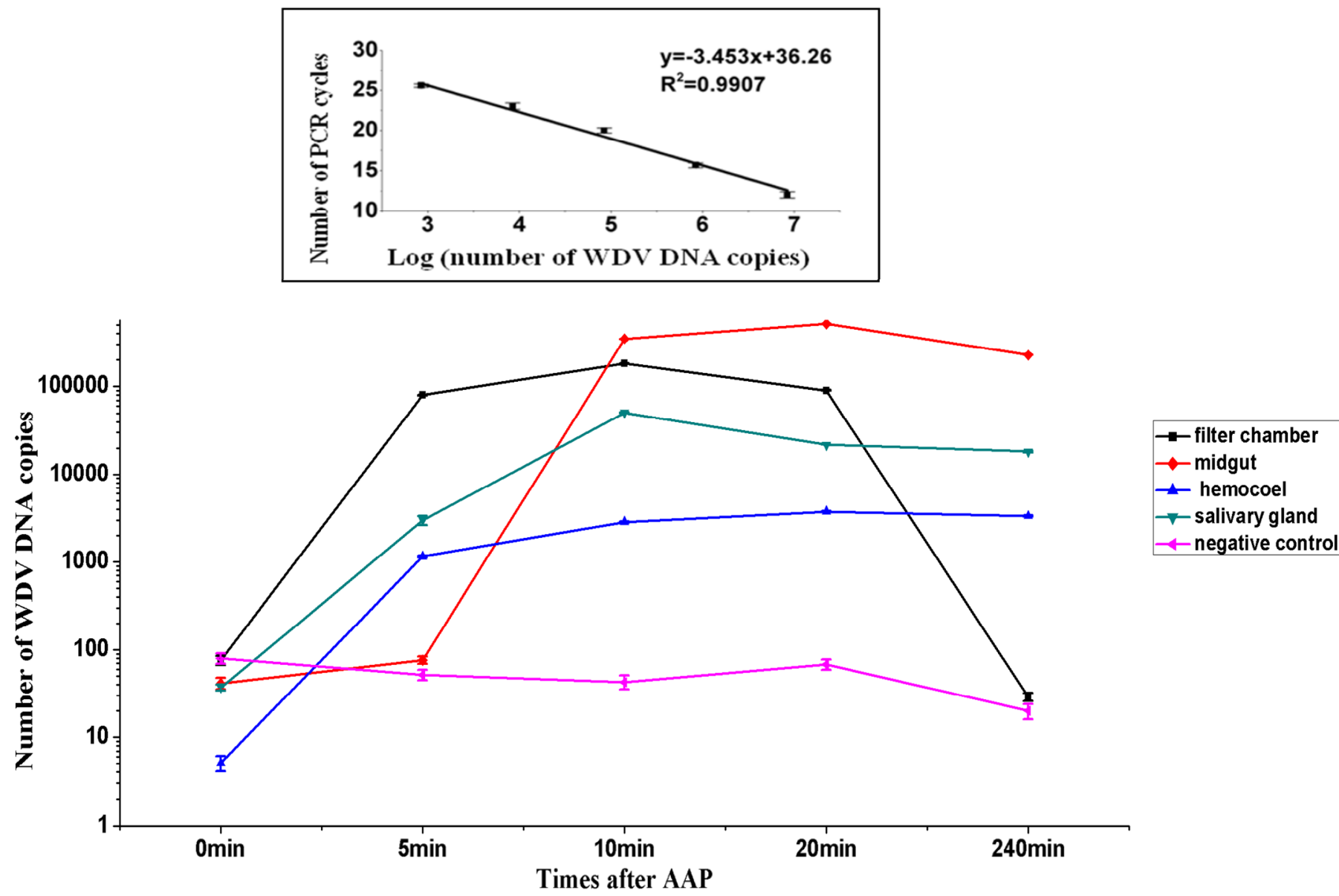

Fig. 2. Wheat dwarf virus (WDV) accumulation in various organs and tissues of leafhoppers after a 5-min acquisition access period (AAP) on WDV-infected wheat plants. Total DNA of hemocytes and different internal organs was extracted from 30 leafhoppers (three repetitions) for a real-time polymerase chain reaction (PCR) assay. The standard curve shows the equation and fit of the line.
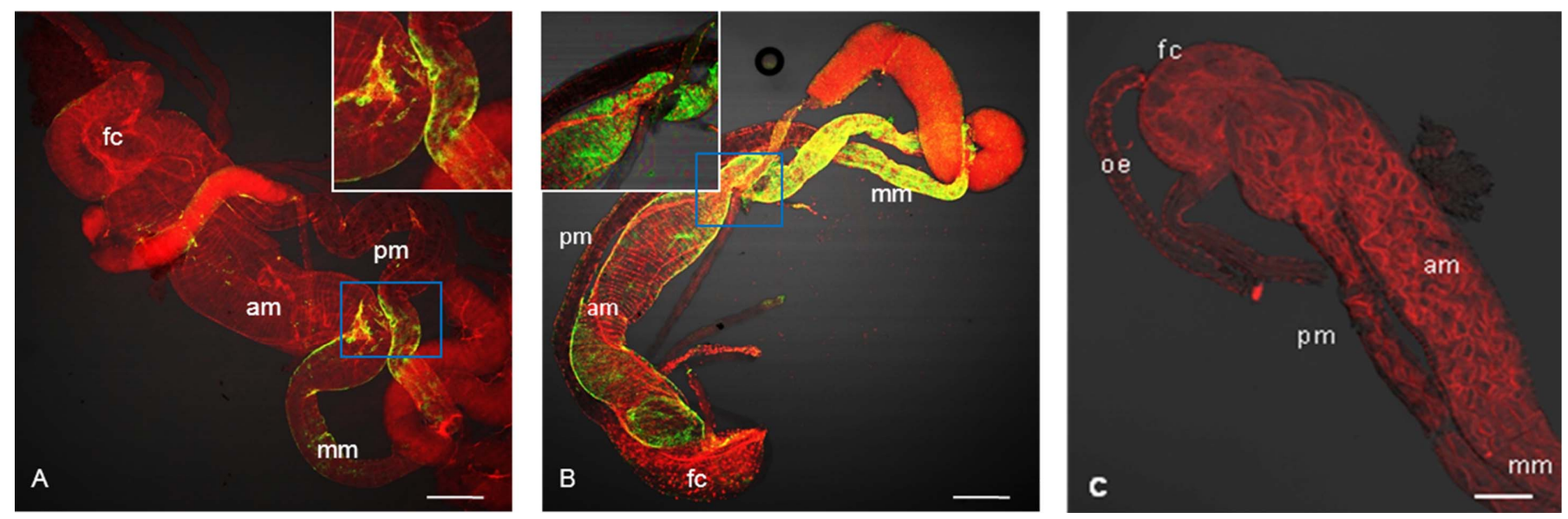

Fig. 3. Wheat dwarf virus (WDV) capsid protein (CP) bound at the midgut. Alimentary canals were incubated with recombinant CP, recombinant replicationassociated protein (Rep), or purified WDV virions. Each treatment was stained with the corresponding immunoglobulin G (anti-CP, anti-Rep, or anti-WDV) with fluorescein-5-isothiocyanate (green) and stained for actin with phalloidin-rhodamine (red), then processed for immunofluorescence microscopy. Abbreviations: $\mathrm{oe}=$ esophagus; $\mathrm{fc}=$ filter chamber; am, $\mathrm{mm}$, and $\mathrm{pm}=$ anterior, middle, and posterior midgut respectively. $\mathbf{A}$, Recombinant $\mathrm{CP}$ bound at the middle midgut and parts of the anterior midgut. B, WDV virions bound at the anterior and middle midgut. C, No bound recombinant Rep can be detected in the alimentary canal. 
hopper had a 5-min PADP, 26.7\% with a 10-min PADP, and $57.8 \%$ with a 20 -min PADP. However, when leafhoppers were fed with the $\mathrm{CP}$ antiserum, the transmission efficiency decreased. None of the wheat plants with a 5- or 10-min PADP was infected and only $8.9 \%$ were infected when the leafhoppers had a $20-\mathrm{min}$ PADP.
Real-time PCR was used to confirm that feeding on the $\mathrm{CP}$ antiserum could successfully block the transmission of WDV. At 20 min PADP, the number of WDV DNA copies detected in cells of the filter chamber, midgut, hemocoel, and salivary glands of the CP-antisera-fed leafhoppers decreased by 69, 62, 64, and $89 \%$, respectively, compared with the basal diet. The results sug-

TABLE 2. Distribution of Wheat dwarf virus in nymphs of Psammotettix alienus that had ingested antiserum to capsid protein (CP), replication-associated protein (Rep), or artificial diet

\begin{tabular}{|c|c|c|c|c|c|c|}
\hline \multirow[b]{2}{*}{ Time PADP ${ }^{x}$} & \multirow[b]{2}{*}{ Antiserum or $\operatorname{diet}^{\mathrm{y}}$} & \multicolumn{5}{|c|}{ Viruliferous leafhoppers $(\%)^{\mathrm{z}}$} \\
\hline & & $\begin{array}{c}\text { Lumen of filter } \\
\text { chamber and midgut }\end{array}$ & $\begin{array}{l}\text { Cells of filter } \\
\text { chamber }\end{array}$ & $\begin{array}{l}\text { Cells of anterior and } \\
\text { middle midgut }\end{array}$ & Hemocoel & $\begin{array}{c}\text { Salivary } \\
\text { glands }\end{array}$ \\
\hline \multirow[t]{3}{*}{$5 \mathrm{~min}$} & $\mathrm{CP}$ & $48.9 \mathrm{a}$ & $0.0 \mathrm{a}$ & $0.0 \mathrm{a}$ & $0.0 \mathrm{a}$ & $0.0 \mathrm{a}$ \\
\hline & Diet & $51.1 \mathrm{ab}$ & $7.8 \mathrm{ab}$ & $0.0 \mathrm{a}$ & $0.0 \mathrm{a}$ & $0.0 \mathrm{a}$ \\
\hline & Rep & $54.4 \mathrm{ab}$ & $13.3 \mathrm{~b}$ & $0.0 \mathrm{a}$ & $0.0 \mathrm{a}$ & $0.0 \mathrm{a}$ \\
\hline \multirow[t]{3}{*}{$10 \mathrm{~min}$} & $\mathrm{CP}$ & $50.0 \mathrm{ab}$ & $8.0 \mathrm{ab}$ & $0.0 \mathrm{a}$ & $0.0 \mathrm{a}$ & $0.0 \mathrm{a}$ \\
\hline & Diet & $53.3 \mathrm{ab}$ & $53.3 \mathrm{c}$ & $0.0 \mathrm{a}$ & $50.0 \mathrm{~b}$ & $50.0 \mathrm{~b}$ \\
\hline & Rep & $56.7 \mathrm{~b}$ & $56.7 \mathrm{c}$ & $0.0 \mathrm{a}$ & $50.0 \mathrm{~b}$ & $50.0 \mathrm{~b}$ \\
\hline \multirow[t]{3}{*}{$20 \mathrm{~min}$} & $\mathrm{CP}$ & $50.0 \mathrm{ab}$ & $15.6 \mathrm{~b}$ & $15.6 \mathrm{~b}$ & $13.3 \mathrm{~b}$ & $10.0 \mathrm{a}$ \\
\hline & Diet & $54.4 \mathrm{ab}$ & $54.4 \mathrm{c}$ & $54.4 \mathrm{c}$ & $54.4 \mathrm{c}$ & $54.4 \mathrm{~b}$ \\
\hline & Rep & $55.6 \mathrm{ab}$ & $55.6 \mathrm{c}$ & $55.6 \mathrm{c}$ & $55.6 \mathrm{c}$ & $55.6 \mathrm{~b}$ \\
\hline
\end{tabular}

${ }^{\mathrm{x}} \mathrm{PADP}=$ post access to diseased plants.

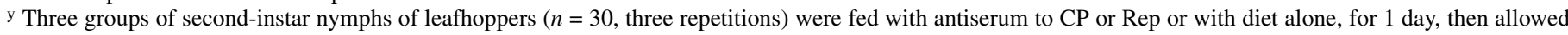
a 5-min acquisition access period on infected wheat before being placed on uninfected wheat seedlings. Insects were then examined by confocal microscopy at the indicated PADP times.

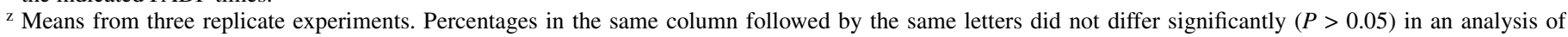
variance for each of the separate times (0 to $240 \mathrm{~min}$ ).
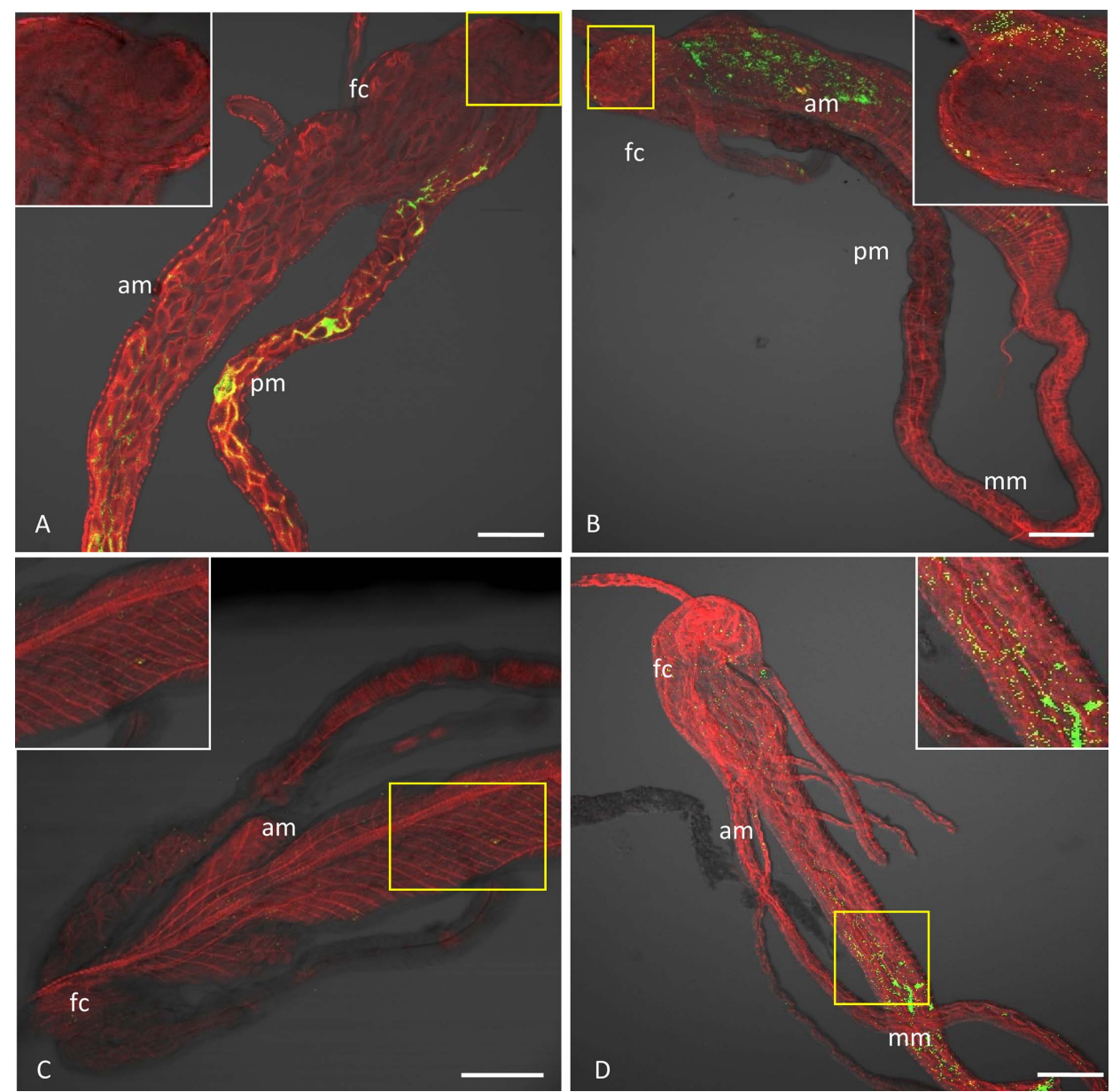

Fig. 4. Wheat dwarf virus (WDV) accumulation in various organs and tissues of leafhoppers fed with capsid protein (CP) immunoglobulin G or with the basal diet as a negative control. Organs were excised and immunolabeled for WDV with fluorescein-5-isothiocyanate (green) and stained for actin with phalloidin-rhodamine (red), then examined by confocal microscopy. Abbreviations: $\mathrm{fc}=$ filter chamber; am, $\mathrm{mm}$, and $\mathrm{pm}=$ anterior, middle, and posterior midgut respectively. A, At 10 min post access to diseased plants (PADP), numerous particles of WDV were detected in the alimentary canal but no virus was detected in the sheath of the filter chamber in the CP-antiserum-fed leafhoppers. B, At 10 min PADP, WDV was detected in the lumen of the alimentary canal and the sheath of the filter chamber in the basal diet-fed leafhoppers. C, At 20 min PADP, the virus had not spread to the muscle of the anterior and middle midgut in the CP antiserum-fed leafhoppers but $\mathbf{D}$, within the same time had spread to the muscle of the anterior and middle midgut in the insects fed only the basal diet. 
gested that the anti-WDV CP antisera blocked WDV transmission from the lumen of the alimentary canal, thus reducing WDV in the cells of the filter chamber, midgut, hemocoel, and salivary glands.

\section{DISCUSSION}

The present work provides insights into the progression of a plant geminivirus within various organs and tissues of its insect vector, $P$. alienus. The details on the sequential movement of WDV in the internal organs of the leafhopper suggested that there may be two pathways for WDV movement through its vector. The first pathway was through the anterior and middle gut to the salivary glands via the hemocoel, similarly to persistent plant viruses in their respective vector (11). The second pathway for WDV movement within its vector is via rapid spread of the virus through the filter chamber directly to the salivary glands via the hemocoel. Our study provides evidence that the filter chamber is a key organ for the rapid movement of WDV and suggests that WDV spreads to the sheath of the filter chamber and then rapidly to the hemocoel. This unique result has important epidemiological implications. Although some begomoviruses have been detected in the filter chamber of their whitefly vector Bemisia tabaci (12), there was no evidence that the virus can spread through the filter chamber and into the hemocoel. WDV spread to the filter chamber within a few minutes after the AAP but remained there for only a few hours, suggesting that this pathway plays only a temporary role in WDV transmission by rapidly allowing translocation of the virus to the salivary glands. WDV spread from the anterior and middle midgut to the salivary glands was slower but persisted longer and was apparently responsible for the typical persistent virus transmission. These differing retention times of WDV in the filter chamber and the gut may be due to varying immune responses against the virus in different organs of the vector (18). WDV CP-immunoreactive antigens and genetic elements were not found in the cells of the posterior midgut, hindgut, or Malpighian tubule at any time. The inability of WDV to enter the hindgut and Malpighian tubule cells could be explained by differing environmental conditions ( $\mathrm{pH}$, for instance) that would inhibit virion-vector receptor interaction.

WDV passed across the leafhopper digestive tract in $\approx 15 \mathrm{~min}$ after a 5-min AAP (Table 1), much faster than that reported for whitefly-transmitted begomoviruses. Beet mild curly top virus passed across the leafhopper digestive tract in $\approx 3 \mathrm{~h}(27)$, Tomato yellow leaf curl virus (TYLCV) was not detected in salivary glands until after a 7-h AAP (24), and Squash leaf curl virus required a minimum of $6-8 \mathrm{~h}$ to be transported to the salivary glands (23). The most likely explanation for the rapid transmission of WDV is that it could be directly transmitted through the filter chamber to the salivary glands before it entered the epithelial cells of the gut. Also, an active mechanism for transmembrane flow via the specific receptor may exist. In our study, WDV could rapidly infect most epithelial cells of the anterior and middle midgut after ingestion and passing into the lumen of the leafhopper digestive tract. Other persistent viruses, when ingested by their vectors, have been reported to only infect one or a few cells at the initial infection site of the gut, then gradually spread to more cells of the gut or the other tissues. For example, Potato leafroll virus was detected in a few cells of the midgut after a 4-h AAP; at $40 \mathrm{~h}$ PADP, it had spread into almost all the intestinal epithelial cells (1). The rapid spread of WDV through the filter chamber but short retention (a few hours) is different from the report of MSV which was mainly and consistently detected in the filter chamber after 3- to 30-day AAPs (1). This phenomenon could be due to differences in feeding duration, immune responses, and a periodic acquisition-related factor.

Using quantitative PCR detection, we found a higher virus content in the intestinal tract than in the hemocoel and salivary gland (Fig. 2). This result suggests that WDV is retained in epithelial cells of the intestinal tract and gradually released to the hemocoel, which may account for the long retention of WDV in the leafhopper vector without replication. Similarly for MSV, the epithelial cells of the midgut inside and outside the filter chamber of $C$. mbila acts as a reservoir in which the acquired virus is retained in an infective form for the lifespan of the leafhopper vector $(1,14)$. Another possible reason for the persistence of WDV is that the GroEL homolog could protect the virus from degradation in the hemocoel. The GroEL homolog in the vectors of luteoviruses and the luteovirus-like Pea enation mosaic virus (genus Enamovirus) prevent the virus from degradation, protecting it from the host's immune response (33).

Acquisition of a virus by an insect vector marks the beginning of an intimate relationship between the virus and the vector and necessitates that the virus has a way to be retained at specific locations within the vector, then eventually released during feeding on a suitable plant (6). The $\mathrm{CP}$ is the viral determinant that participates in geminivirus retention and transmission $(3,5)$. It has been studied for a number of whitefly-transmitted geminiviruses, including TYLCV and Bean yellow mosaic virus $(9,20)$. In our study, we provided direct evidence that the $\mathrm{CP}$ plays an essential role in the retention and movement of WDV in the vector: (i) the recombinant $\mathrm{CP}$ could specifically bind at the anterior and middle midgut, while the nonstructural protein Rep could not; and (ii) antiserum to the $\mathrm{CP}$ prevented WDV transmission in the leafhopper vector.

We have described in detail WDV spread in its leafhopper vector and confirmed that the $\mathrm{CP}$ is involved in WDV retention in the anterior and middle midgut of the leafhopper vector. This is the first report that the filter chamber is a key organ for WDV invading the hemocoel of the leafhopper, resulting in a rapid transmission of the virus. The molecular mechanisms enabling the spread of WDV into and out of the filter chamber need further investigation.

\section{ACKNOWLEDGMENTS}

This research was supported by the Special Fund for Agro-scientific Research in the Public Interest (201303021) and the Natural Science Foundation of China (NSFC31272017). Y. Wang and Q. Mao contributed equally to this work. We thank A. Fereres (ICA, CSIC, Spain) and S. Gray (Cornell University) for improving the English text.

\section{LITERATURE CITED}

1. Ammar, E., Gargani, D., Lett, J. M., and Peterschmitt, M. 2009. Large accumulations of Maize streak virus in the filter chamber and midgut cells of the leafhopper vector Cicadulina mbila. Arch. Virol. 154:255-262.

2. Ammar, E., and Hogenhout, S. A. 2005. Use of immunofluorescence confocal laser scanning microscopy to study distribution of the bacterium corn stunt spiroplasma in vector leafhoppers (Hemiptera: Cicadellidae) and in host plants. Ann. Entomol. Soc. Am. 98:820-826.

3. Azzam, O., Frazer, J., De La Rosa, D., Beaver, J. S., Ahlquist, P., and Maxwell, D. P. 1994. Whitefly transmission and efficient ssDNA accumulation of bean golden mosaic geminivirus require functional coat protein. Virology 204:289-296.

4. Bernardo, P., Golden, M., Akram, M., Naimuddin, Nadarajan, N., Fernandez, E., Granier, M., Rebelo, A. G., Peterschmitt, M., Martin, D. P., and Roumagnac, P. 2013. Identification and characterization of a highly divergent geminivirus: evolutionary and taxonomic implications. Virus Res. 177:35-45.

5. Briddon, R. W., Pinner, M. S., Stanley, J., and Markham, P. G. 1990. Geminivirus coat protein gene replacement alters insect specificity. Virology 177:85-94.

6. Chen, A. Y., Walker, G. P., Carter, D., and Ng, J. C. 2011. A virus capsid component mediates virion retention and transmission by its insect vector. Proc. Natl. Acad. Sci. USA 108:16777-16782.

7. Chen, H., Chen, Q., Omura, T., Uehara-Ichiki, T., and Wei, T. 2011. Sequential infection of Rice dwarf virus in the internal organs of its insect vector after ingestion of virus. Virus Res. 160:389-394.

8. Gutierrez, C. 1999. Geminivirus DNA replication. Cell. Mol. Life Sci. 56:313-329. 
9. Hammond, J., and Hammond, R. W. 1989. Molecular cloning, sequencing and expression in Escherichia coli of the bean yellow mosaic virus coat protein gene. J. Gen. Virol. 70:1961-7194.

10. Harrison, B. D. 1985. Advances in geminivirus research. Annu. Rev. Phytopathol. 23:55-82.

11. Hogenhout, S. A., Ammar, E. D., Whitfield, A. E., and Redinbaugh, M. G. 2008. Insect vector interactions with persistently transmitted viruses. Annu. Rev. Phytopathol. 46:327-359.

12. Hunter, W. B., Hiebert, E., Webb, S. E., Tsai, J. H., and Polston, J. E. 1998. Location of geminiviruses in the whitefly Bemisia tabaci (Homoptera: Aleyrodidae). Plant Dis. 82:1147-1151.

13. Jia, D., Guo, N., Chen, H., Akita, F., Xie, L., Omura, T., and Wei, T. 2012. Assembly of the viroplasm by viral non-structural protein Pns10 is essential for persistent infection of rice ragged stunt virus in its insect vector. J. Gen. Virol. 93:2299-2309.

14. Lett, J. M., Granier, M., Hippolyte, I., Grondin, M., Royer, M., Blanc, S., Reynaud, B., and Peterschmitt, M. 2001. Spatial and temporal distribution of geminiviruses in leafhoppers of the genus Cicadulina monitored by conventional and quantitative polymerase chain reaction. Phytopathology 92:65-74.

15. Liu, Y., Wang, B., Vida, G., Karolyi-Cseplo, M., Wu, B., Wu, Y., and Wang, X. 2012. Genomic analysis of the natural population of Wheat dwarf virus in wheat from China and Hungary. J. Integr. Agric. 11:20202027.

16. Markham, P. G., Pinner, M. S., and Boulton, M. I. 1984. The transmission of Maize streak virus by leafhoppers, a new look at host adaptation. Bull. Soc. Entomol. Suisse 57:431-432.

17. Markham, P. G., Pinner, M. S., Mesfin, T., Nebbache, S., Briddon, R. W., and Medina, V. 1988. Geminiviruses, and their interaction with vectors. Pages 63-67 in: Annu. Rep. John Innes Cent., Norwich.

18. Medeiros, R. B., Resende, R. D. O., and de Ávila, A. C. 2004. The plant virus Tomato spotted wilt tospovirus activates the immune system of its main insect vector, Frankliniella occidentalis. J. Virol. 78:4976-4982.

19. Ng, J. C., Tian, T., and Falk, B. W. 2004. Quantitative parameters determining whitefly (Bemisia tabaci) transmission of Lettuce infectious yellows virus and an engineered defective RNA. J. Gen. Virol. 85:2697-2707.

20. Noris, E., Vaira, A. M., Caciagli, P., Masenga, V., Gronenborn, B., and Accotto, G. P. 1998. Amino acids in the capsid protein of Tomato yellow leaf curl virus that are crucial for systemic infection, particle formation, and insect transmission. J. Virol. 72:10050-10057.

21. Ramsell, J. N. E., Lemmetty, A., Jonasson, J., Andersson, A., Sigvald, R., and Kvarnheden, A. 2008. Sequence analyses of Wheat dwarf virus isolates from different hosts reveal low genetic diversity within the wheat strain. Plant Pathol. 57:834-841.

22. Rojas, M. R., Hagen, C., Lucas, W. J., and Gilbertson, R. L. 2005. Exploiting chinks in the plant's armor: evolution and emergence of geminivirus. Annu. Rev. Phytopathol. 43:361-394.

23. Rosell, R. C., Torres-Jerez, I., and Brown, J. K. 1999. Tracing the geminivirus-whitefly transmission pathway by polymerase chain reaction in whitefly extracts, saliva, hemolymph, and honeydew. Phytopathology 89:239-246.

24. Rubinstein, G., and Czosnek, H. 1997. Long-term association of Tomato yellow leafcurl virus with its whitefly vector Bemisia tabaci: effect on the insect transmission capacity, longevity and fecundity. J. Gen. Virol. $78: 2683-2689$

25. Schalk, H. J., Matzeit, V., Schiller, B., Schell, J., and Gronenborn, B. 1989. Wheat dwarf virus, a geminivirus of graminaceous plants need splicing for replication. EMBO J. 8:359-364.

26. Schubert, J., Habekuss, A., Kazmaier, K., and Jeske, H. 2007. Surveying cereal-infecting geminiviruses in Germany-Diagnostics and direct sequencing using rolling circle amplification. Virus Res. 127:61-70.

27. Soto, M. J., and Gilbertson, R. L. 2003. Distribution and rate of movement of the Curtovirus Beet mild curly top virus (Family Geminiviridae) in the beet leafhopper. Phytopathology 93:478-484.

28. Spinelli, S., Campanacci, V., Blangy, S., Moineau, S., Tegoni, M., and Cambillau, C. 2006. Modular structure of the receptor binding proteins of Lactococcus lactis phages. The RBP structure of the temperate phage TP901-1. J. Biol. Chem. 281:14256-14262.

29. Takahashi, Y., Omura, T., Shohara, K., and Tsuchizaki, T. 1991. Comparison of four serological methods for practical detection of ten viruses of rice in plants and insects. Plant Dis. 75:458-461.

30. Tian, T., Rubio, L., Yeh, H. H., Crawford, B., and Falk, B. W. 1999. Lettuce infectious yellows virus: in vitro acquisition analysis using partially purified virions and the whitefly Bemisia tabaci. J. Gen. Virol. 80:1111-1117.

31. Tsai, J. H., Joan, L., and Perrier, J. L. 1996. Morphology of the digestive and reproductive systems of Dalbulus maidis and Graminella nigrifrons (Homoptera: Cicadellidae). Fla. Entomol. 79:563-578.

32. Vacke, J. 1961. Wheat dwarf virus disease. Biol. Plant 3:228-233.

33. Van den Heuvel, J. F., Bruyere, A., Hogenhout, S. A., Ziegler-Graff, V., Brault, V., Verbeek, M., Van der Wilk, F., and Richards, K. 1997. The Nterminal region of the luteovirus readthrough domain determines virus binding to Buchnera GroEL and is essential for virus persistence in the aphid. J. Virol. 71:7258-7265.

34. Wu, B., Melcher, U., Guo, X., Wang, X., Fan, L., and Zhou, G. 2008. Assessment of codivergence of Mastreviruses with their plant hosts. BMC Evol. Biol. 8:335.

35. Xie, J., Wang, X., Liu, Y., Peng, Y., and Zhou, G. 2007. First report of the occurrence of WDV in wheat in China. Plant Dis. 91:109-113.

36. Zhang, X., Zhou, G., and Wang, X. 2010. Detection of Wheat dwarf virus (WDV) in wheat and vector leafhopper (Psammotettix alienus Dahlb.) by real-time PCR. J. Virol. Methods 169:416-419. 